\title{
Case Report: The first familial hCG syndrome in a Chinese
}

\section{family [version 1; peer review: 2 approved]}

\section{Ling-Yin Hung (D1,2, Mei-Tik Leung1, Toby Chun-Hei Chan1, Hoi-Ning Cheung1, Wai-Hon Li ${ }^{3}$, Yui-Shing Cheung ${ }^{3}$, Assumpta Sze-Man Wong ${ }^{3}$, Chi-Chung Shek ${ }^{1}$, Sammy Pak-Lam Chen ${ }^{1}$}

${ }^{1}$ Chemical Pathology Laboratory, Department of Pathology, Queen Elizabeth Hospital, Kowloon, Hong Kong

${ }^{2}$ Chemical Pathology Laboratory, Department of Pathology, Princess Margaret Hospital, Hong Kong

${ }^{3}$ Department of Obstetrics \& Gynaecology, Queen Elizabeth Hospital, Kowloon, Hong Kong

V1 First published: 08 Jun 2021, 10:458

https://doi.org/10.12688/f1000research.53636.1

Latest published: 08 Jun 2021, 10:458

https://doi.org/10.12688/f1000research.53636.1

\section{Abstract}

Familial hCG syndrome is a rare and benign cause of elevated serum beta human chorionic gonadotropin (hCG). We present here a case of familial hCG syndrome diagnosed in a Hong Kong Chinese family, which we believe to be the first reported in Chinese. A 38-year-old woman presented with incidental finding of persistently elevated hCG, analytically confirmed both in urine and blood. Extensive radiological and biochemical work-up were performed but were negative for pregnancy and malignancy. Testing of another asymptomatic family member revealed unexplained elevation of serum hCG, confirming the diagnosis of familial hCG syndrome. Knowledge and awareness of this entity among clinicians are important to avoid unnecessary investigations and treatment in affected families.

\section{Keywords}

familial hCG syndrome, hCG, human chorionic gonadotropin, gestational trophoblastic disease, ectopic pregnancy, tumour marker, autosomal inheritance

\section{Open Peer Review \\ Approval Status \\ 1 \\ 2 \\ version 1 \\ 08 Jun 2021
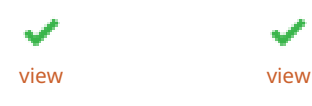

1. Weldon Chiu, Auckland City Hospital,

Auckland, New Zealand

2. Ravi Krishna Cheemakurthi, Krishna IVF

Clinic, Visakhapatnam, India

Any reports and responses or comments on the article can be found at the end of the article. 
Corresponding author: Sammy Pak-Lam Chen (chenpls@ha.org.hk)

Author roles: Hung LY: Conceptualization, Investigation, Methodology, Writing - Original Draft Preparation; Leung MT:

Conceptualization, Investigation, Methodology, Writing - Original Draft Preparation; Chan TCH: Investigation, Writing - Review \&

Editing; Cheung HN: Investigation, Writing - Review \& Editing; Li WH: Investigation, Writing - Review \& Editing; Cheung YS:

Investigation, Writing - Review \& Editing; Wong ASM: Investigation, Writing - Review \& Editing; Shek CC: Investigation, Supervision,

Writing - Review \& Editing; Chen SPL: Conceptualization, Investigation, Methodology, Supervision, Writing - Review \& Editing

Competing interests: No competing interests were disclosed.

Grant information: The author(s) declared that no grants were involved in supporting this work.

Copyright: $\odot 2021$ Hung LY et al. This is an open access article distributed under the terms of the Creative Commons Attribution License, which permits unrestricted use, distribution, and reproduction in any medium, provided the original work is properly cited.

How to cite this article: Hung LY, Leung MT, Chan TCH et al. Case Report: The first familial hCG syndrome in a Chinese family [version 1; peer review: 2 approved] F1000Research 2021, 10:458 https://doi.org/10.12688/f1000research.53636.1

First published: 08 Jun 2021, 10:458 https://doi.org/10.12688/f1000research.53636.1 


\section{Introduction}

Familial hCG syndrome is a rare but benign cause of elevated serum/urine hCG. To date, fewer than 20 families have been reported worldwide in the literature ${ }^{1-3}$. Patients present with an otherwise unexplained elevation in serum/urine hCG, and diagnosis is established by exclusion of other causes of elevated hCG and testing of family members. An autosomal dominant pattern of inheritance was observed, although the molecular mechanism has been poorly defined. We present here a case of familial hCG syndrome diagnosed in Hong Kong, which we believe to be the first reported family in Chinese.

\section{Case presentation}

A 38-year-old Chinese woman, a veterinary surgeon, was referred for investigation of persistent unexplained elevation in serum beta human chorionic gonadotropin (hCG) levels first revealed in a positive urine pregnancy test for the investigation of abdominal pain in August 2020. Apart from a history of menorrhagia and iron deficiency anaemia, the patient had unremarkable past health. She was not on any drugs or supplement and had never been sexually active. Family history was unremarkable. Blood tests showed stable elevation of total beta-hCG ranging from 93-112 IU/L by Roche Elecsys $\mathrm{HCG}+\beta$ assay over the subsequent five months. Transabdominal ultrasound of the pelvis showed no intrauterine sac, and no abnormality was detected in the uterus and ovaries. Pituitary hormones, including serum thyroid-stimulating hormone (TSH), luteinizing hormone ( $\mathrm{LH})$, follicle stimulating hormone $(\mathrm{FSH})$ and prolactin levels were normal. Biochemical findings of the patient are summarized in Table 1.

Due to the discordant clinical and biochemical findings, analytical interference of hCG assay was suspected and a series of interference studies were performed (Table 2). Serial dilution

Table 1. Summary of biochemical results of the patient.

\begin{tabular}{|c|c|c|}
\hline Assay & Result & Reference intervals \\
\hline \multicolumn{3}{|l|}{ Serum results } \\
\hline \multicolumn{3}{|l|}{$\mathrm{hCG}$} \\
\hline Roche Elecsys hCG+ $\beta$ & $98 \mathrm{IU} / \mathrm{L}$ & $\leq 6 \mathrm{IU} / \mathrm{L}$ \\
\hline Abbott Architect Total $\beta-h C G$ & $30 \mathrm{IU} / \mathrm{L}$ & $<5 \mathrm{IU} / \mathrm{L}$ \\
\hline Siemens Immulite 2000 total $\beta$-hCG & $424 \mathrm{IU} / \mathrm{L}$ & $<5 \mathrm{IU} / \mathrm{L}$ \\
\hline Beckman DxI total $\beta-h C G$ & 37 IU/L & $<5 \mathrm{IU} / \mathrm{L}$ \\
\hline Hyperglycosylated hCG (hCG-H) & $<0.5 \mu \mathrm{g} / \mathrm{L}$ & $<1.0 \mu \mathrm{g} / \mathrm{L}$ \\
\hline $\mathrm{LH}$ & $3.6 \mathrm{IU} / \mathrm{L}$ & $\begin{array}{l}\text { Follicular } 2.4-12.6 \\
\text { Ovulation } 14.0-95.6 \\
\text { Luteal } 7.7-58.5\end{array}$ \\
\hline $\mathrm{FSH}$ & $2.1 \mathrm{IU} / \mathrm{L}$ & $\begin{array}{l}\text { Follicular } 3.5-12.5 \\
\text { Ovulation } 4.7-21.5 \\
\text { Luteal } 1.7-7.7\end{array}$ \\
\hline Prolactin & $251 \mathrm{mIU} / \mathrm{L}$ & 102 - $496 \mathrm{mIU} / \mathrm{L}$ \\
\hline $\mathrm{TSH}$ & $3.08 \mathrm{mIU} / \mathrm{L}$ & $0.27-4.20 \mathrm{mIU} / \mathrm{L}$ \\
\hline CEA & $<1.8 \mu \mathrm{g} / \mathrm{L}$ & $\leq 4.7 \mu \mathrm{g} / \mathrm{L}$ \\
\hline CA125 & $11 \mathrm{U} / \mathrm{mL}$ & $\leq 35 \mathrm{U} / \mathrm{mL}$ \\
\hline AFP & $<2 \mathrm{IU} / \mathrm{mL}$ & $\leq 6 \mathrm{IU} / \mathrm{mL}$ \\
\hline \multicolumn{3}{|l|}{ Urine results } \\
\hline Roche Elecsys hCG+ $\beta$ & $168 \mathrm{IU} / \mathrm{L}$ & NA \\
\hline \multicolumn{3}{|l|}{ hCG: human chorionic gonoadotropin } \\
\hline \multicolumn{3}{|l|}{ LH: Luteinizing hormone } \\
\hline \multicolumn{3}{|l|}{ FSH: Follicle stimulating hormone } \\
\hline \multicolumn{3}{|l|}{ TSH: Thyroid stimulating hormone } \\
\hline \multicolumn{3}{|l|}{ CEA: Carcinoembryonic antigen } \\
\hline \multicolumn{3}{|l|}{ CA125: Cancer antigen 125} \\
\hline AFP: Alpha fetoprotein & & \\
\hline
\end{tabular}




\section{Table 2. Results of interference studies performed on patient's serum specimen.}

\begin{tabular}{|l|l|}
\hline Dilution recovery & $\begin{array}{l}\text { hCG in neat sample: } 112 \text { IU/L } \\
\text { hCG with x5 dilution: } 106 \text { IU/L (Recovery: 95\%) } \\
\text { hCG with x10 dilution: } 103 \text { IU/L (Recovery: 92\%) }\end{array}$ \\
\hline Heterophilic blocking tube & $\begin{array}{l}\text { hCG in neat sample: } 112 \text { IU/L } \\
\text { hCG post blocking tube treatment: } 107 \text { IU/L (Recovery: 96\%) }\end{array}$ \\
\hline PEG precipitation & $\begin{array}{l}\text { hCG in neat sample: } 105 \text { IU/L } \\
\text { hCG in supernatant after 1:1 PEG treatment: } 100 \text { IU/L (Recovery: } 95 \%)\end{array}$ \\
\hline
\end{tabular}

hCG: human chorionic gonoadotropin

PEG: Polyethylene glycol (PEG 6000)

study was performed on the Roche Elecsys $\mathrm{HCG}+\beta$ assay with manufacturer diluent in 1:4 and 1:9 dilutions, which showed linear recovery. Satisfactory recovery was observed in serum hCG level on the Roche assay after treatment with heterophilic blocking tube (Scantibodies Laboratory, Inc). Polyethylene glycol (PEG) precipitation study was performed by mixing $200 \mu \mathrm{L}$ of patient sample with $200 \mu \mathrm{L}$ of $25 \%$ (w/v) PEG 6000 (Sigma Aldrich). The sample was then incubated at room temperature for 10 minutes and centrifuged at $9500 \times \mathrm{g}$ for 10 minutes. hCG levels were assayed by the Roche Elecsys $\mathrm{HCG}+\beta$ assay in the supernatant. Recovery was satisfactory compared to the hCG result in the neat untreated serum sample. Aliquots of serum were sent to three local laboratories for analyses using different analytical platforms (Abbott Architect, Beckman DxI and Siemens Immulite 2000), all confirming elevation in beta-hCG but to variable extents, with the highest hCG result obtained using Siemens Immulite 2000 (Table 1). Spot urine total beta-hCG was checked by the Roche Elecsys HCG $+\beta$ assay and measured 168 IU/L.

To look for underlying tumours, tumour markers including carcinoembryonic antigen, cancer antigen 125 and alpha fetoprotein were checked but were not elevated. Hyperglycosylated hCG (hCG-H) was undetectable $(<0.5 \mu \mathrm{g} / \mathrm{L})$ using the Nichols Advantage hCG-H assay (Nichols Institute Diagnostics, San Clemente, California). Whole body positron emission tomography-computed tomography, magnetic resonance imaging of the pituitary, abdomen and pelvis were unrevealing. Oesophagogastroduodenoscopy was negative.

As biochemical and radiological work-up could not explain the persistently elevated hCG, familial hCG syndrome was considered in this otherwise asymptomatic patient. Blood hCG test was arranged for one female sibling who also had never been sexually active, and the level was elevated (37 IU/L). There were no other family members available for testing. The diagnosis of familial hCG syndrome was thus established. This is to the best of our knowledge the first case of familial hCG syndrome reported in Chinese.

\section{Discussion}

Human chorionic gonadotropin is a heterodimeric glycoprotein hormone produced by placental syncytiotrophoblast during pregnancy $^{4}$. It comprises of a common alpha subunit shared between LH, FSH and TSH, and a unique beta subunit that has been shown to be encoded by at least seven genes ${ }^{4,5}$. In blood circulation, hCG exists in various forms arising from post-translational glycosylation and its degradation in the liver and kidneys ${ }^{4}$. Apart from pregnancy, increased levels may be seen in gestational trophoblastic diseases, and a number of tumours including germ cell tumours, non-small cell lung cancer $^{6}$, as well as squamous cell carcinoma of the head and neck region ${ }^{7,8}$, in which other $\mathrm{hCG}$ forms such as free beta-subunit or hyperglycosylated form may predominate ${ }^{4}$. In postmenopausal women or patients with gonadal insufficiency, sulfated hCG secreted from the pituitary is a frequent cause of mildly elevated hCG. Occasionally, elevated hCG may arise from exogenous administration in doping athletes or as a dietary supplement. In a patient who has otherwise unexplained elevation of hCG discordant with clinical findings, analytical interferences, such as heterophilic antibody interference, are important causes that should be excluded. According to data from USA, hCG Reference Service, among 424 cases of positive hCG with no history of gestational trophoblastic disease or malignancy and pregnancy excluded, the commonest aetiologies were quiescent gestational trophoblastic disease (32\%), analytical interference $(25 \%)$ and pituitary hCG (23\%), followed by other malignant conditions $(15 \%)$ and exogenous intake $(1 \%)^{1}$.

The above differentials were, however, unlikely in our patient based on the extensive negative biochemical and radiological work-up. Intrauterine and extrauterine pregnancies were unlikely given the negative pelvic imaging. Active gestational trophoblastic disease and occult malignancies were less likely with the negative findings on extensive whole-body imaging and undetectable hyperglycosylated hCG. The normal LH and FSH ruled out pituitary hCG. Analytical interferences were less likely although not entirely excluded by the normal recovery on serial dilution, treatment with heterophilic antibody blocking tube and PEG precipitation. The detection of hCG in the urine provides further evidence for a genuine increase in endogenous hCG levels. The negative work-up and persistent elevation in hCG led to the suspicion of familial hCG syndrome, which was subsequently confirmed with testing of hCG level in an asymptomatic family member. 
Familial hCG syndrome is a rare but benign cause of elevated hCG. Serum hCG from reported cases in literature ranged from $<1.0-216 \mathrm{IU} / \mathrm{L}$, and levels showed fluctuation with time on serial testing ${ }^{2}$. Antibody profiling by Cole demonstrated the predominance of free $\beta$-subunit and $\beta$-subunit missing the C-terminal peptide in affected patients ${ }^{1}$. Both forms are biologically inactive, thus explaining the unaffected fertility in these patients. The presence of these uncommon hCG variants may account for the difference in hCG results across different analytical platforms. Studies comparing the reactivity of available international standards and international reference preparations with sandwich immunoassays on major analyzers have shown vastly different recoveries towards different hCG variants $^{9-11}$. For instance, the Siemens Immulite 2000 total $\beta$-hCG assay, which was shown to have equimolar detection of $\beta$-subunit missing $\mathrm{C}$-terminal peptide and nicked hCG $\beta$, consistently returned the highest hCG result among the four platforms tested in our patient. The incongruent results across multiple immunoassay platforms may provide additional support to the diagnosis of familial hCG syndrome, as direct measurements of the various hCG subtypes are not readily available in routine clinical practice. Knowledge of the assay reactivity towards the different variants may aid in the interpretation of discordant results.

Reliable markers or diagnostic tests specific to familial hCG syndrome are lacking. Diagnosis relies on careful exclusion of common causes and testing of family members, the former often includes performing a number of costly diagnostic imaging. Of note, a lack of response to a trial of methotrexate therapy has been proposed as one of the diagnostic criteria for familial hCG syndrome in female patients of reproductive age to exclude ectopic pregnancy, which, however, is not without risk. Further research into the underlying molecular mechanisms and structural characterization of the variants may identify better means of establishing a diagnosis, and may allow detection of concurrent physiological or pathological hCG elevations in diagnosed patients.

In conclusion, we report here the first case of familial hCG syndrome in a Chinese family. Given the rarity of the entity and the lack of readily available biochemical markers, familial hCG syndrome remains a diagnosis by exclusion. Knowledge and awareness of this disorder among clinicians are important to avoid over investigations and unnecessary treatment, and in offering reassurance to affected patients and family members.

\section{Data availability}

All data underlying the results are available as part of the article and no additional source data are required.

\section{Consent}

Written informed consent for publication of clinical and laboratory details was obtained from the patient.
1. Cole LA: Familial hCG Syndrome.J Reprod Immunol. 2012; 93(1): 52-7. PubMed Abstract | Publisher Full Text

2. Cole LA, Butler S: Familial hcg syndrome: Production of variable, degraded or mutant forms of hcg. J Reprod Med. 2014; 59(9-10): 435-42. PubMed Abstract

3. Tan A, van der Merwe AM, Low X, et al.: Familial HCG syndrome: A diagnostic challenge. Gynecol Oncol Rep. 2014; 10: 47-8. PubMed Abstract | Publisher Full Text | Free Full Text

4. Cole LA: Biological functions of hCG and hCG-related molecules. Reprod Biol Endocrinol. 2010; 8: 102

PubMed Abstract | Publisher Full Text | Free Full Text

5. Talmadge K, Boorstein WR, Fiddes JC: The Human Genome Contains Seven Genes for the beta-Subunit of Chorionic Gonadotropin but Only One Gene for the beta-Subunit of Luteinizing Hormone. DNA. 1983; 2(4): 281-9. PubMed Abstract | Publisher Full Text

6. Khattri S, Vivekanandarajah A, Varma S, et al:: Secretion of beta-human chorionic gonadotropin by non-small cell lung cancer: A case report. J Med Case Rep. 2011; 5: 19.

PubMed Abstract | Publisher Full Text | Free Full Text
7. Miller C, McQuade M, MacCallum J, et al.: Persistently elevated hCG in a patient with no clear evidence of pregnancy. Clin Chim Acta. 2020; 510: 703-6.

PubMed Abstract | Publisher Full Text

8. Turner JH, Ross H, Richmon J: Secretion of beta-HCG from squamous cell carcinomas of the head and neck. Otolaryngol Head Neck Surg. 2010; 143(1): 169-70.

PubMed Abstract | Publisher Full Text

9. Sturgeon $\mathrm{CM}$, Berger $\mathrm{P}$, Bidart JM, et al.: Differences in recognition of the 1 st WHO international reference reagents for hCG-related isoforms by diagnostic immunoassays for human chorionic gonadotropin. Clin Chem. 2009; 55(8): 1484-91.

PubMed Abstract | Publisher Full Text

10. Whittington J, Fantz CR, Gronowski AM, et al:: The analytical specificity of human chorionic gonadotropin assays determined using WHO International Reference Reagents. Clin Chim Acta. 2010; 411(1-2): 81-5. PubMed Abstract | Publisher Full Text

11. Cole LA, DuToit S, Higgins TN: Total hCG tests. Clin Chim Acta. 2011; 412(23-24): 2216-22.

PubMed Abstract | Publisher Full Text 


\section{Open Peer Review}

\section{Current Peer Review Status:}

\section{Version 1}

Reviewer Report 28 June 2021

https://doi.org/10.5256/f1000research.57046.r87100

(C) 2021 Cheemakurthi R. This is an open access peer review report distributed under the terms of the Creative Commons Attribution License, which permits unrestricted use, distribution, and reproduction in any medium, provided the original work is properly cited.

\section{Ravi Krishna Cheemakurthi}

Center for Assisted Reproduction, Krishna IVF Clinic, Visakhapatnam, Andhra Pradesh, India

I appreciate authors for their effort in presenting the case report with clinical findings and proper diagnostic parameters. My suggestion is it would have been more exciting if authors would have tried to find the genetic cause behind the clinical condition, because in many rare disorders it is very difficult to find a family member with similar clinical condition. As of now it is just a case with familial hCG syndrome which was first case in a Chinese family.

Is the background of the case's history and progression described in sufficient detail? Yes

Are enough details provided of any physical examination and diagnostic tests, treatment given and outcomes?

Yes

Is sufficient discussion included of the importance of the findings and their relevance to future understanding of disease processes, diagnosis or treatment?

Yes

Is the case presented with sufficient detail to be useful for other practitioners? Yes

Competing Interests: No competing interests were disclosed.

Reviewer Expertise: My area of research is in the field of reproductive genetics especially in the pharmocogenomic aspects of LH and FSH supplementation in COS protocols

I confirm that I have read this submission and believe that I have an appropriate level of expertise to confirm that it is of an acceptable scientific standard. 
Reviewer Report 16 June 2021

https://doi.org/10.5256/f1000research.57046.r87096

(C) 2021 Chiu W. This is an open access peer review report distributed under the terms of the Creative Commons Attribution License, which permits unrestricted use, distribution, and reproduction in any medium, provided the original work is properly cited.

\section{Weldon Chiu}

Department of Chemical Pathology, Labplus, Auckland City Hospital, Auckland, New Zealand

A very well written and worked-up case report on this rare but clinically important condition to avoid over-investigation or worse still, potentially invasive and harmful treatments offered for a benign condition. Though there is no gold standard test, the arguments in favour of this diagnosis are scientifically sound. My only suggestion is that especially with the rarity of this condition, if there are any additional information including serial hCG results and/or any free beta HCG results e.g. from Autodelfia or Johnson and Johnson free beta-hCG platform (designed mainly for maternal serum screening), they would be worth mentioning in the report too.

Is the background of the case's history and progression described in sufficient detail? Yes

Are enough details provided of any physical examination and diagnostic tests, treatment given and outcomes?

Yes

Is sufficient discussion included of the importance of the findings and their relevance to future understanding of disease processes, diagnosis or treatment?

Yes

Is the case presented with sufficient detail to be useful for other practitioners? Yes

Competing Interests: No competing interests were disclosed.

Reviewer Expertise: Gastrointestinal and liver related clinical biochemistry; General chemical pathology. Had encountered 2 families with familial hCG syndrome.

I confirm that I have read this submission and believe that I have an appropriate level of expertise to confirm that it is of an acceptable scientific standard. 
The benefits of publishing with F1000Research:

- Your article is published within days, with no editorial bias

- You can publish traditional articles, null/negative results, case reports, data notes and more

- The peer review process is transparent and collaborative

- Your article is indexed in PubMed after passing peer review

- Dedicated customer support at every stage

For pre-submission enquiries, contact research@f1000.com 